\title{
Bilateral giant inguinoscrotal Hernia: psychosocial issues and a new classification
}

\author{
*Akpo EE \\ Department of Surgery, Delta State University Teaching Hospital, Oghara, Nigeria
}

\begin{abstract}
Background: Bilateral giant inguinoscrotal hernias pose challenging psychosocial problems to the patient. The engulfed phallus and hernia size are socially embarrassing and may make penetration during coitus increasingly difficult and uncomfortable. This paper presents a classification and the psychosocial aspects of bilateral giant inguinoscrotal hernias. Methods: A prospective study of patients with bilateral giant inguinoscrotal hernia in which the phallus was completely engulfed by the swelling, managed by this author between 2002 and 2011 in both urban and rural practice in Nigeria and Sierra Leone was reviewed and analyzed using a simple frequency distribution.

Results: Eleven patients with bilateral giant inguinoscrotal hernias were reviewed. Age range 63-86 years. Mean age 73.73 ( \pm 6.96SD) years. The reason for delayed presentation was financial constraint. Six patients $(54.55 \%)$ presented due to continuous refusal of coitus by their partners. Sexual satisfaction was poor in all the patients $(100.00 \%)$. All the patients $(100.00 \%)$ had poor self-esteem and poor socialization habits as a result of continuous ridicule from peers and colleagues.

Conclusion: To improve quality of life of the elderly, there is the need for early awareness campaigns and provision of improved access to free surgical health care services particularly in rural African communities.

Keywords: Bilateral giant inguinoscrotal hernia, classification, quality of life

African Health Sciences 2013; 13(1): 166 - 170 http://dx.doi.org/10.4314/ahs.v13i1.24
\end{abstract}

\section{Introduction}

A giant inguinoscrotal hernia is defined as a hernia extending below the knee level in the standing position or that is bigger than the patient's head ${ }^{1,2}$. Bilateral giant inguinoscrotal hernia has not yet been defined in the world literature. The rarity of bilateral giant inguinoscrotal hernias may account for their non-classification till date. For the purpose of uniformity therefore, here define a bilateral giant inguinoscrotal hernia as a bilateral inguinoscrotal hernia extending below the midthigh in the standing position and completely engulfing the phallus (figure 1). This group of hernias I have also tried to further sub-classify into four types based on the state of the phallus, scrotal skin, the abdomen or inability to micturate. These types of hernias are more common in elderly men who live in rural areas without surgical facilities, those who do heavy work while ignoring their disease or in those who are unable to pay for surgical intervention ${ }^{1,3,4}$. Mobility, voiding and coital difficulties impede on the quality of life of this group

\footnotetext{
*Corresponding author:

Emmanuel E. Akpo

Department of Surgery

Delta State University Teaching Hospital

Oghara, Delta State

Nigeria

Email: marieakpo@yahoo.com
}

of patients ${ }^{3,4}$. This paper thus presents a classification and the psychosocial aspects of bilateral giant inguinoscrotal hernias.

\section{Methods}

A ten-year prospective analysis was carried out of bilateral giant inguinoscrotal hernias seen between January 2002 and December 2011 by this author at Kambia Government hospital, Kambia, Sierra Leone, Eastern Regional Hospital, Kenema, Sierra Leone, Dalhatu Araf Specialist Hospital, Lafia, Nasarawa State, Nigeria, Federal Medical Center, Makurdi, Benue State, Nigeria, free rural medical missions programmes organized in various rural communities in the different states in Nigeria under the auspices of Christian Medical Fellowship (United States of America), New Life Foundation (United Kingdom), Pro-Health International (Nigeria), Global Medical Missions (Nigeria) and Rural Health Scheme of the Delta State Government, Delta state, Nigeria.

A structured questionnaire was designed including the patients bio-data, region of residence (rural/urban), occupation, duration of symptoms prior to presentation, reasons for delay in presentation, reasons why the patient is now presenting, if his phallus is completely buried by the mass, if he is able to reduce the mass and if he does, 
if the phallus is completely exposed in its entire length during coitus, if the phallus is completely engulfed by the mass during erection, if the patient gets sexual satisfaction in his current state, whether or not he satisfies his partner during sexual intercourse, if there are skin ulcerations. The proforma also included questions on the attitude of peers and colleagues, self esteem and patient's public socialization status. Only bilateral giant inguinoscrotal hernias with the phallus buried by the mass were included in this study (figure 1). All other types of giant inguinoscrotal hernias were excluded. The data were analyzed and presented using simple frequency distribution. Patient's consent was sort before questionnaire was administered.

\section{Results}

There were eleven patients with bilateral giant inguinoscrotal hernia seen and meeting the inclusion over the study period, January 2002 and December 2011. Age range was 63-86 years. Mean age was
73.73 ( $\pm 6.96 \mathrm{SD})$ years. The duration of symptoms ranged from 14-51 years with a mean of 26 $( \pm 12.21 \mathrm{SD})$ years. The main reason for delay in presentation was financial constraint (table 2). Six patients $(54.55 \%)$ presented as a result of continuous refusal of coitus by their partners. Four patients $(36.36 \%)$ presented because they were no longer able to penetrate their partners during sexual intercourse. Self gratification during coitus was poor in all the patients $(100.00 \%)$. All the patients $(100.00 \%)$ had poor self-esteem and poor socialization habits as a result of continuous ridicule from peers and colleagues. This eventually affected their farming activities resulting in a drop in the income in ten patients $(90.91 \%)$. The only patient whose income did not drop was a religious leader whose salary continued to run. Walking was increasingly difficult for all the patients $(100.00 \%)$. The quality of life was negatively affected in all patients.

\section{Table 1: Akpo's classification of bilateral giant inguinoscrotal hernia}

\begin{tabular}{|c|c|}
\hline Grades & Description \\
\hline Grade 0 & The phallus is incompletely engulfed in its detumescence state \\
\hline \multirow[t]{3}{*}{ Grade 1} & The phallus is completely engulfed in its detumescence state \\
\hline & 1a. The complete phallic length is exposed following erection with the hernia reduced \\
\hline & 1b. Part of the phallus is exposed in its tumescence state \\
\hline Grade 2 & The phallus is completely engulfed in its tumescence state \\
\hline \multirow[t]{4}{*}{ Grade 3} & Presence of complications e.g. skin necrosis/ulceration, urine retention, acute abdomen \\
\hline & 3a: Skin necrosis/ulceration \\
\hline & 3b: Urinary retention \\
\hline & 3c: Acute abdomen from intestinal obstruction \\
\hline
\end{tabular}

Table 2: Demographic data of eleven patients presenting with bilateral giant inguinoscrotal hernia

\begin{tabular}{cclllll}
\hline Patients & Age & Residence & Occupation & $\begin{array}{l}\text { Duration of } \\
\text { symptoms before } \\
\text { presentation } \\
\text { (years) }\end{array}$ & Country & Reason for delay \\
\hline A & 86 & Rural & Farmer & 42 & Sierra Leone & Finance \\
B & 65 & Rural & Farmer & 14 & Nigeria & Finance \\
C & 77 & Urban & Religious leader & 31 & Nigeria & Finance \\
D & 68 & Rural & Farmer & 17 & Nigeria & Finance \\
E & 63 & Rural & Farmer & 21 & Nigeria & Finance \\
F & 81 & Rural & Farmer & 36 & Nigeria & Finance \\
G & 69 & Urban & Laborer & 18 & Nigeria & Finance \\
H & 70 & Rural & Fisherman & 20 & Nigeria & Finance \\
I & 74 & Rural & Farmer & 16 & Sierra Leone & Finance \\
J & 83 & Rural & Farmer & 51 & Nigeria & Finance \\
K & 75 & Rural & Farmer & 20 & Nigeria & Finance \\
\hline
\end{tabular}




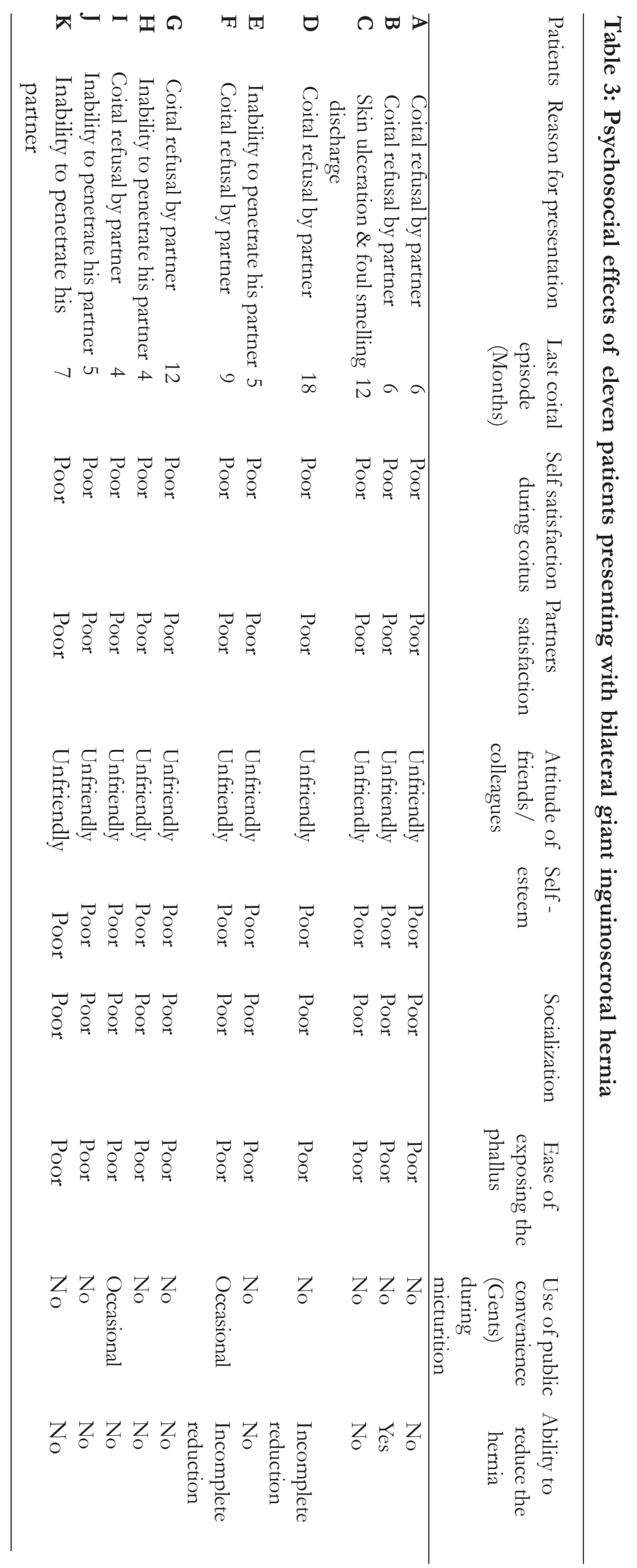




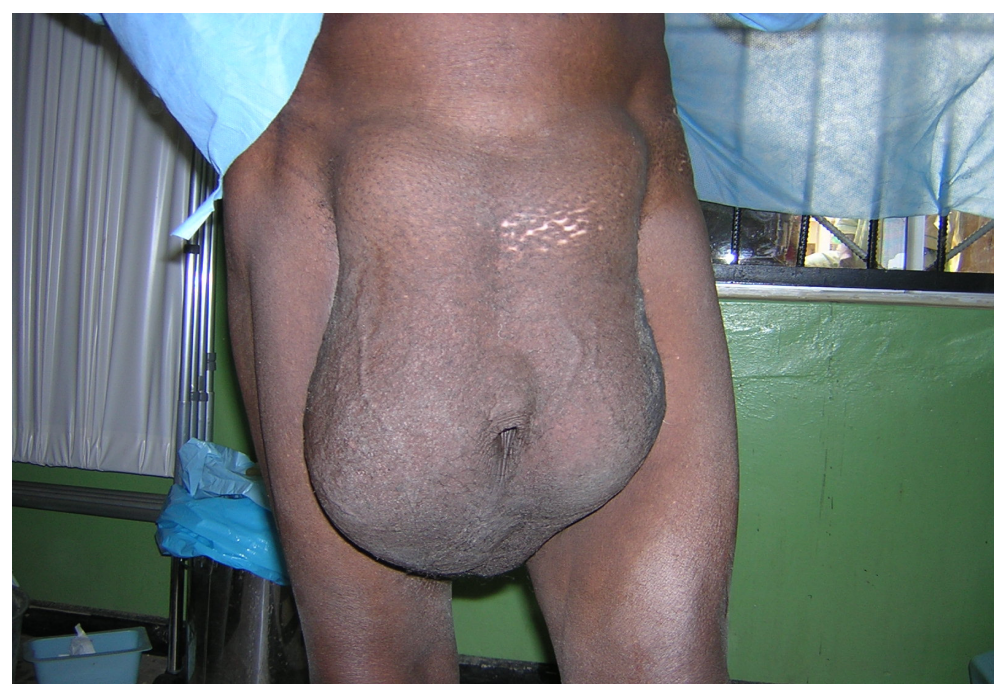

Figure 1: Bilateral giant inguinoscrotal hernia

\section{Discussion}

Giant inguinoscrotal hernias are rare accounting for only $2.81-5 \%$ of all inguinal hernias ${ }^{3,5}$. Bilateral giant inguinoscrotal hernias are rarer accounting for only $12.5 \%$ of all giant inguinoscrotal hernias in a recent publication $^{3}$. Till date there has been no classification of bilateral giant inguinoscrotal hernia probably due to its rarity. For the purpose of uniformity therefore, I have defined a bilateral giant inguinoscrotal hernia as a bilateral inguinoscrotal hernia extending below the midthigh in the standing position and completely engulfing the phallus (figure I).

It is noteworthy that in all the patients reviewed, the phallus was already engulfed by the mass prior to extension of the bilateral inguinal hernia mass below the midthigh irrespective of the size of the phallus. This group of hernias I have also tried to further sub-classify into four types based on the state of the phallus, scrotal skin, the abdomen and/ or inability to micturate: Grade 0: The phallus is incompletely engulfed in its detumescence state. Grade 1: The phallus is completely engulfed in its detumescence state. Grade 1a: The complete phallic length is exposed following tumescence with the hernia reduced. Grade 1b: Part of the phallus is exposed in its tumescence state. Such hernias are usually not completely reducible due to adhesions. Penetration during coitus is not satisfactory and the hernia mass causes some obstruction to coital maneuvers. Grade 2: The phallus is completely engulfed in its tumescence state. Coital penetration is impossible in this group of patients. Such patients become emotionally depressed as they do not satisfy their sexual desires. The increased size of the mass and its weight also completely impedes coital access particularly when reduction is difficult or impossible as a result of adhesions. Grade 3: complicated bilateral giant inguinoscrotal hernias (3a: Skin necrosis/ ulceration, 3b: urinary retention, 3c: acute abdomen) (table 1). The underlying cause of not meeting the sexual needs in these groups of patients is dual fold: the 'buried phallus' and the coital obstruction created by the mass.

This condition is commoner in men dwelling in rural communities in the developing countries who lack access to surgical facilities, in patients who neglect their disease or are unable to afford the cost of surgery ${ }^{1,3,4,6}$. While all the patients reviewed were aware that the hernia will require surgical intervention, they all agreed to problem of finance being the limiting factor to surgical intervention. The main reason why they presented at the time they all presented was purely social: either due to coital refusal from the sexual partner or inability to penetrate (table 3). In the African tradition, men marry more than one wife in most cultures and/ or have many concubines and the need to meet their own sexual desires and those of their spouses is immense. If the desires are not met, wives or concubines will usually find alternatives or divorce the men. The fear of the spouse leaving the patient with the dilemma of a bilateral giant inguinoscrotal hernia adds to the psychological effects created by the hernia. 
Additional problems created aside from the complications of the hernia include difficulty in lying down, sitting or walking ${ }^{7}$. The size of the hernia restricts their mobility immensely affecting their work capacity, income generation and quality of life ${ }^{8}$. This study indicates that friends and colleagues ridiculed these patients and this may be a contributory factor to the poor self esteem, poor work capacity and poor income stream of these patients.

The average duration of symptoms before presentation was $26 \pm 12.21$ years. This has increased from an average of 14.5 years in an earlier study ${ }^{9}$. In the majority of cases in the study of Osifo et al, $61.2 \%$ of the patients were unaware of the use of surgery as a modality for treatment of giant inguinoscrotal hernia. In that study, only $25.4 \%$ of the study population had financial constraints. In the current study which also confirms a recent study by Akhator and Oside ${ }^{2}$ in the African environment, financial constraint accounted for the real reason for delay in surgical intervention in all $(100.00 \%)$ of cases. This may portray the increasing level of poverty in the African continent particularly in the rural communities.

Skin manifestation in the form skin necrosis and ulceration has been previously documented ${ }^{6,7,10}$, and ${ }^{11}$. In the current series, skin manifestation accounted for $9.10 \%$ of the cases reviewed. This group of patients presenting with skin manifestation has been classified as having grade 3 a disease (table 1).

In extremely rare cases where the urinary bladder and part of the ureters form part of the contents of the giant hernia sac, urinary retention may occur ${ }^{5,10}$. Acute urinary retention may also occur from voiding difficulties as the scrotum tightens around the 'buried' penis ${ }^{5,7}$. This group of patients have been classified as grade $3 \mathrm{~b}$. Bowel obstruction also forms an imminent complication which may occur from adhesions ${ }^{5}$. Patients presenting with this complication have been classified as grade $3 \mathrm{c}$.

The sexual life of patients with bilateral inguinoscrotal hernia is greatly affected by the size of the hernia and the difficulty of achieving full penile length at tumescence to enable full and deep vaginal penetrations. This greatly impairs sexual satisfaction for both the patient and his partner. Additionally, being shy to approach the female partner for sex with such a giant hernia has been reported as negatively affecting the patient's psychosocial wellbeing ${ }^{3}$. In the current study, all the patients $(100 \%)$ indicate that neither they nor their partners are satisfied with their sexual lives. This prompted refusal of coitus by sexual partners in $6(54.55 \%)$ of the cases. Four of the patients $(36.36 \%)$ presented because they were no longer able to penetrate their partners. The psychological trauma of not being able to fulfill sexual desires in life prompted these patients to present themselves during free health care programmes organized in their communities. The emotional needs of patients with bilateral giant inguinoscrotal hernia needs some further evaluation in future studies.

\section{Conclusion}

Poor self-esteem and coital satisfaction of both partners alongside overall poor quality of life of men with bilateral giant inguinoscrotal hernias call for the need for early awareness campaigns particularly in rural African communities. Additionally, there is the need to improve access of these elderly patients in such communities to free surgical health care services.

\section{References}

1. Davey WW. Hernia. In Davey WW, ed. Companion to Surgery in Africa. 1st edition. Churchill Livingstone, Edinburgh. 1968: 280294.

2. Akhator A, Oside C. Giant inguinoscrotal hernias in Warri, Nigeria. AJTMBR 2011; 2 (1): 91-95.

3. Hodgkinson DJ, McIlrath DC. Scrotal reconstruction for giant inguinal hernias. Surg Clin North Am 1984; 64(2): 307-313.

4. Ozalp N, Akten OA, Tez M. Giant scrotal hernia in an elderly man. Eur J Surg Sci 2011;2(1):23-2

5. Gupta V, Sharma AK, Chrungoo RK. A giant inguinoscrotal hernia. JK Science. 2007; 9 (4): 200202.

6. El Saadi AS, AI Wadan AH, Hamerna S. An approach to a giant inguinoscrotal hernia. Hernia 2005; 9:277-279.

7. Al Sarakbi W, Agrawal A, Taffinder N. A giant inguinoscrotal hernia: a case report and review of the literature. Grand Rounds 2005;5: 46-48.

8. Vasiliadis K, Knaebel H, Djakovic N. et al. Challenging surgical management of a giant inguinoscrotal hernia: Report of a case. Surg. Today 2010; 40 (7): 684-687.

9. Osifo O, Amusan TI. Mehendel FV, Taams KO, Kingsworth AN. Repair of a giant inguinoscrotal hernia. British J Plastic Surgery 2000; 53: 525-9.

10. Vano-Galvan S, Guisado-Vasco P, Jaen P. Giant inguinoscrotal hernia. Aust Fam Physician. 2009; 38(4):222-3.

11. Kovachev LS, Paul AP, Chowdhary P et al. Regarding extremely large inguinal hernias with a contribution of two cases. Hernia 2010;14(2):193-7. 